\title{
Reproducibility of Reports of Past History, Smoking, Drinking and Dietary Habits Obtained by a Personal Interview for a Case-Control Study on Liver Cirrhosis and Hepatocellular Carcinoma
}

\author{
ITSUYO HIROHATA, KATSUHIRO FUKUDA, AKIRA SHIBATA, \\ GENJIRO YAMAGUCHI AND TOMIO HIROHATA* \\ Department of Public Health, Kurume University School of Medicine, \\ Kurume, 830 and ${ }^{*}$ Kyushu University School of Medicine, \\ Fukuoka, 812 Japan
}

Received for publication October 11, 1991

\begin{abstract}
Summary: The reproducibility of responses on life style measurements observed during a personal interview was assessed by a test-retest method. Fifty-one apparently healthy male subjects were interviewed twice, mostly within a 10 week interval. Responses on past history, smoking and drinking habits yielded relatively high intraclass correlation coefficients between the two interviews, as compared to the responses on dietary habits for the previous 1 to 2 years, which varied depending on the food items.
\end{abstract}

Key words: reproducibility of interview responses - past history - smoking habits - drinking habits - dietary habits

\section{Introduction}

The necessity of validity and reproducibility in the assessment of epidemiological information has been recognized, particularly for information on dietary habits. Many extensive studies have been published on this subject in the United States and West European countries (Morgan et al. 1978; Block et al. 1982; Lee-Han et al. 1989). Japanese epidemiologists have recently begun to explore this subject and a review paper has been published (Fukuda et al. 1991).

A hospital-based case-control study on liver cirrhosis (LC) and hepatocellular carcinoma (HCC) was initiated in April, 1986 in the Fukuoka and Saga Prefectures located in Northern Kyushu, Japan. Incident cases of LC and/or HCC, aged 40-69, were identified through the inpatient records of Kurume University Hospital, and their hospital controls matched for age, sex, residency of prefecture and time of hospitalization were obtained from inpatients of the two affiliated general hospitals in Kurume. A questionnaire was developed to collect information on their past history, lifetime experiences of cigarette smoking and alcohol drinking, as well as recent dietary habits. Interviews were performed in person by a well-trained interviewer using this questionnaire. The interviews were taperecorded and checked against the questionnaires by the authors.

In the present study, the reproducibility of reports on the questionnaire about life style measurements was assessed by a test-retest method in accordance with the case-control study on LC and HCC mentioned above. Reproducibility was defined as the extent of agreement of responses obtained by two consecutive interviews with the same subject. 


\section{Materials and Methods}

The patients for the case-control study on LC and HCC were predominantly male, thus male volunteers were recruited mainly from clerical personnel at the Kurume Community Center, and from participants in various activities held in the center during the study period. Interviews were performed twice in an identical manner with the case-control study in a secluded place in the area of work or activity. The subjects were not informed of the plan to repeat the interview at a later date. The time-interval between the two interviews was intended to be more than 1 month and less than 2 months, and most (78\%) of the second round interviews were performed within 10 weeks. Sixty-four men were interviewed from September through November, 1986, of whom 51 (80\%) finished the 2nd interview. Of the remaining 13 men, 11 could not be contacted for the 2 nd interview because of withdrawal from the activities or because of illnesses. Two other men refused to be re-interviewed. Each interview took approximately $30 \mathrm{mi}$ nutes.

The following analyses were performed on the 51 men; 3 were age $40-49,10$ were $50-59,33$ were $60-69$ and 5 were $70-73$. Study items included the subject's past history of several diseases, history of blood transfusions, family history of liver disease, and life style measurements such as smoking, drinking and dietary habits.

Items on smoking included lifetime smoking status: either non-smoker, exsmoker or current smoker, age began smoking, age stopped smoking and the daily amount of cigarettes smoked at any stage of smoking habit. Since the use of tobacco products other than cigarettes was very limited, smokers were defined as those who had smoked cigarettes every day, at least 1 pack (20 cigarettes) per week, for 1 year or longer. Non-smokers were defined as those who had never smoked, had smoked less than 1 pack per week or had smoked for less than 1 year. The total amount of smoking was quantified by the accumulated BrinkmanCoates Indices for lifetime (Brinkman et al. 1962).

A detailed drinking history, such as age began drinking, age stopped drinking, the kinds and amount of alcoholic beverages consumed during any stages of drinking habits, were obtained for their lifetime. The amount of alcohol intake was quantified by the unit "drink" which is the amount of alcoholic beverage containing $23 \mathrm{ml}$ of pure ethanol. The accumulated amount of alcohol intake was the sum, calculated by the unit of "drink-years" which was obtained by multiplying the number of "drinks" for all types of beverages by the number of years of their consumption. Drinkers were defined as those who had consumed any alcoholic beverages more than once a week, at least one "drink" per week for one year or longer.

The dietary information focused on the usual dietary habits during the previous 1 to 2 years. Subjects were asked about their frequency of intake of 12 food items, using a list of 7 categories as indicated in the footnote of Table 5. A picture of 9 representative green-yellow vegetables was also used to render the subjects familiar with the naming. The average intake was also queried for 5 of these food items, using food models of common portion sizes. The semi-quantitative weekly consumption of each food item was then estimated by multiplying the frequency of intake per week by the average amount eaten each time.

Reproducibility was assessed for all of the items by the paired t test, Wilcoxon matched-pairs signed-ranks test and intraclass correlation analysis. 


\section{Results}

Responses of the subjects during the 1st interview on past history of diseases, such as diabetes mellitus, blood transfusions and family history of liver disease agree well with those obtained during the 2nd interview, as shown in Table 1.

The responses from the 1st interview on current smoking status were completely consistent with those from the 2nd interview. The reproducibility of responses on other smoking habits, however, were not complete, as shown in Table 2. The intraclass correlation coefficients (ICCs) were statistically significant and the paired $t$ values for comparison between the 1st and 2nd interviews were all below 1.96. This may indicate that responses on smoking habits ob- served in the present study were free from both systematic bias and significant discrepancy in the responses between the two interviews.

Although the lifetime history of drinking habits was complicated to be described in adequately quantitative terms, reproducibility was assessed from items, such as drinking frequency for the previous 1 to 2 years, age began drinking, and the accumulated amount of alcohol consumption both for a lifetime and by age 40 . A cut-off at an age of 40 was selected because many patients for the case-control study on LC and HCC began to reduce or stop their alcohol intake around that age due to impairment of liver function. The responses on drinking frequency for the previous 1 to 2 years during the 1st and 2nd interviews are

TABLE 1

Reproducibility of responses on past history and family history from two interviews with 51 men

\begin{tabular}{|c|c|c|c|c|c|c|}
\hline & \multicolumn{2}{|c|}{ agreed } & \multicolumn{2}{|c|}{ disagreed } & \multirow{2}{*}{$\begin{array}{l}\% \text { of } \\
\text { exact } \\
\text { agree- } \\
\text { ment }\end{array}$} & \multirow{2}{*}{$\begin{array}{l}\text { intraclass } \\
\text { correlation } \\
\text { coefficient }\end{array}$} \\
\hline & "no" & "yes" & $\begin{array}{l}\text { "no" } \\
\text { then } \\
\text { "yes" }\end{array}$ & $\begin{array}{l}\text { "yes" } \\
\text { then } \\
\text { "no" }\end{array}$ & & \\
\hline \multicolumn{7}{|l|}{ Past history of ; } \\
\hline DM, HYPT, TB ${ }^{\dagger \dagger}$ & 25 & 22 & 2 & 2 & 92.2 & $0.845^{*}$ \\
\hline $\begin{array}{l}\text { heart or lung } \\
\text { diseases }\end{array}$ & 33 & 16 & 2 & 0 & 96.1 & $0.913^{*}$ \\
\hline GI tract diseases & 25 & 21 & 5 & 0 & 90.2 & $0.806^{*}$ \\
\hline liver diseases & 45 & 5 & 0 & 1 & 98.0 & $0.900 *$ \\
\hline other diseases & 31 & 16 & 4 & 0 & 92.2 & $0.831^{*}$ \\
\hline $\begin{array}{l}\text { major trauma or } \\
\text { operations }\end{array}$ & 30 & 20 & 0 & 1 & 98.0 & $0.960^{*}$ \\
\hline $\begin{array}{l}\text { blood transfu- } \\
\text { sion } t+t\end{array}$ & 40 & 7 & 0 & 1 & 97.9 & $0.923^{*}$ \\
\hline \multicolumn{7}{|l|}{ Family history of; } \\
\hline liver diseases & 44 & 6 & 1 & 0 & 98.0 & $0.913^{*}$ \\
\hline $\begin{array}{l}\dagger \text { "no" then "yes" } \\
\text { "yes" in the 2nd } \\
\dagger^{\dagger} \text { diabetes mellitus } \\
\dagger^{\dagger \dagger} \text { excluding } 3 \text { men } \\
* \mathrm{P}<0.05 \text {. }\end{array}$ & $\begin{array}{l}\text { Idica } \\
\text { nter } \\
\text { hyp } \\
\text { who }\end{array}$ & $\begin{array}{l}\text { that } \\
\text { N. } \\
\text { ension } \\
\text { lied " }\end{array}$ & berc & eplied & $10 "$ in & he lst and \\
\hline
\end{tabular}


TABLE 2

Reproducibility of responses on smoking habits from two interviews with 51 men

\begin{tabular}{|c|c|c|c|c|c|}
\hline & \multirow{2}{*}{$\begin{array}{l}\text { number of } \\
\text { subjects }\end{array}$} & \multicolumn{2}{|c|}{ number or mean } & \multirow{2}{*}{$\begin{array}{l}\text { paired } \\
\mathrm{t} \\
\text { value }\end{array}$} & \multirow{2}{*}{$\begin{array}{l}\text { intraclass } \\
\text { correlation } \\
\text { coefficient }\end{array}$} \\
\hline & & $1 \mathrm{st}^{\dagger}$ & $2 \mathrm{nd}^{\dagger}$ & & \\
\hline smoking status ${ }^{\dagger \dagger}$ & 51 & $5,17,29$ & $5,17,29$ & - & $1.000^{*}$ \\
\hline age began smoking & 46 & 22.1 & 22.2 & -0.231 & $0.721^{*}$ \\
\hline age stopped smoking & 17 & 53.1 & 52.2 & 1.376 & $0.978^{*}$ \\
\hline $\begin{array}{l}\text { total amount for } \\
\text { lifetime } \text { lif† }^{\dagger \dagger}\end{array}$ & 46 & 665.8 & 682.0 & -0.663 & $0.914^{*}$ \\
\hline $\begin{array}{l}\text { total amount by } \\
\text { age } 40^{\dagger+\dagger}\end{array}$ & 46 & 298.2 & 304.7 & -0.401 & $0.861^{*}$ \\
\hline
\end{tabular}

$\dagger$ at 1st or 2nd interview, respectively.

$t^{\dagger}$ three figures in the 2 nd or 3 rd column correspond number of non-smoker, ex-smoker or current smoker, respectively.

${ }^{\dagger \dagger}$ for ex- or current cigarette smokers; total amount smoked by the accumulated Brinkman-Coates Indices.

$* \mathrm{P}<0.05$.

TABLE 3

Reproducibility of responses on drinking frequency for previous 1 to 2 years from two interviews with 51 men

\begin{tabular}{|c|c|c|c|c|c|}
\hline \multirow{2}{*}{ 1st interview } & \multicolumn{5}{|c|}{ 2nd interview } \\
\hline & 1 & 2 & 3 & 4 & total \\
\hline 1. every day & 20 & 3 & 0 & 0 & 23 \\
\hline 2. 1-6 times per week & 1 & 8 & 1 & 0 & 10 \\
\hline 3. do not drink ${ }^{\dagger}$ & 0 & 2 & 16 & 0 & 18 \\
\hline 4. unknown & 0 & 0 & 0 & 0 & 0 \\
\hline total & 21 & 13 & 17 & 0 & 51 \\
\hline
\end{tabular}

$\dagger$ includes those who have never drunk and those who drunk less than once a week, less than one "drink" per week and/ or for less than one year.

$Z$ (Wilcoxon matched-pairs signed-ranks test) $=-0.338$ Intraclass correlation coefficient $=0.912, \mathrm{P}<0.05$.

shown in Table 3. Forty-five $\%$ of men during the 1st interview were classified as "every day" drinkers, while $35 \%$ "do not drink". Responses to drinking frequency from the two interviews generally agree. As shown in Table 4, the differences between the mean values for age began drinking and the accumulated amount of alcohol consumed for a life- time or by age 40 were insignificant and the corresponding ICCs were significantly positive.

With regard to the frequency of food intake for the previous 1 to 2 years as shown in Table 5 , the percentage of exact agreement between the two interviews distributed from 33 for green-yellow vegetables to 86 for boiled rice and the ICCs 
TABLE 4

Reproducibility of responses on age began drinking and accumulated amount of alcohol intake from two interviews with 42 men

\begin{tabular}{|c|c|c|c|c|c|}
\hline & \multirow{2}{*}{$\begin{array}{l}\text { number } \\
\text { of } \\
\text { subjects }\end{array}$} & \multicolumn{2}{|c|}{ mean value } & \multirow{2}{*}{$\begin{array}{l}\text { paired } \\
\mathrm{t} \\
\text { value }\end{array}$} & \multirow{2}{*}{$\begin{array}{l}\text { intraclass } \\
\text { correlation } \\
\text { coefficient }\end{array}$} \\
\hline & & $1 \mathrm{st}^{\dagger}$ & $2 \mathrm{nd}^{\dagger}$ & & \\
\hline age began drinking & 42 & 28.6 & 28.0 & 0.358 & $0.449 *$ \\
\hline $\begin{array}{l}\text { accumulated amount } \\
\text { for lifetime }{ }^{\dagger \dagger}\end{array}$ & 42 & 1041.9 & 1169.4 & -1.346 & $0.856^{*}$ \\
\hline $\begin{array}{l}\text { accumulated amount } \\
\text { by age } 40^{\dagger \dagger}\end{array}$ & 39 & 405.6 & 458.1 & -0.908 & $0.788^{*}$ \\
\hline
\end{tabular}

$\dagger$ at lst or 2 nd interview, respectively.

$\dagger \dagger$ in the unit of "drink-years".

$* \mathrm{P}<0.05$.

TABLE 5

Reproducibility of responses on food intake frequency ${ }^{\dagger}$ from two interviews with 51 men

\begin{tabular}{lccc}
\hline \multicolumn{1}{c}{ food item } & $\begin{array}{c}\text { \% of exact } \\
\text { agreement }\end{array}$ & $\begin{array}{l}\text { Z value } \\
\text { between } \\
\text { 1st \& 2nd } \\
\text { interview }\end{array}$ & $\begin{array}{l}\text { intraclass } \\
\text { correlation } \\
\text { coefficient }\end{array}$ \\
\hline boiled rice & 86.3 & $1.014^{\dagger \dagger \dagger}$ & $0.794^{*}$ \\
to-fu (bean curd) & 52.9 & 0.086 & $0.604^{*}$ \\
beans & 49.0 & $-2.121^{*}$ & $0.664^{*}$ \\
nuts & 64.7 & 0.740 & $0.527^{*}$ \\
fish & 54.9 & -1.338 & $0.659^{*}$ \\
fish cooked in oil & 58.8 & -0.052 & $0.570^{*}$ \\
meat, chicken & 43.1 & -0.746 & $0.564^{*}$ \\
meat, chicken cooked in oil & 47.1 & 0.144 & $0.420^{*}$ \\
eggs & 68.6 & 0.646 & $0.610^{*}$ \\
milk & 68.6 & 0.905 & $0.840^{*}$ \\
fresh vegetables & 39.2 & -0.412 & $0.669^{*}$ \\
green-yellow vegetables & 33.3 & -1.633 & $0.405^{*}$ \\
\hline
\end{tabular}

$\dagger$ seven categories; none, 1-3 times per month, 1-3 times per week, 4-6 times per week, once a day, twice a day, and 3 times a day.

$\dagger \dagger$ by Wilcoxon matched-pair signed-ranks test.

${ }^{\dagger \dagger}$ positive figure indicates a greater frequency during the lst interview as compared to the 2nd interview.

$* \mathrm{P}<0.05$. 
TABLE 6

Reproducibility of responses on amounts of intake for 5 food items from two interviews with 51 men

\begin{tabular}{|c|c|c|c|c|}
\hline \multirow{2}{*}{ food item } & \multicolumn{2}{|c|}{ mean value } & \multirow{2}{*}{$\begin{array}{l}\text { paired } \\
\mathrm{t} \\
\text { value }\end{array}$} & \multirow{2}{*}{$\begin{array}{l}\text { intraclass } \\
\text { correlation } \\
\text { coefficient }\end{array}$} \\
\hline & $1 s t^{\dagger}$ & $2 \mathrm{nd}^{\dagger}$ & & \\
\hline boiled rice ${ }^{\dagger \dagger}$ & 3387.5 & 3294.1 & 0.774 & $0.784^{*}$ \\
\hline to $-f u$ (bean curd) $\dagger \dagger$ & 411.1 & 472.5 & -1.140 & $0.584^{*}$ \\
\hline $\operatorname{fish}^{\dagger \dagger}$ & 313.3 & 335.9 & -0.608 & $0.663^{*}$ \\
\hline $\operatorname{eggs}^{\dagger \dagger}$ & 268.6 & 245.1 & 0.913 & $0.368^{*}$ \\
\hline milk ${ }^{\dagger \dagger}$ & 982.1 & 936.3 & 0.434 & $0.703^{*}$ \\
\hline
\end{tabular}

$\dagger$ at 1 st or 2 nd interview, respectively.

$\dagger^{\dagger}$ in grams per week.

$* \mathrm{P}<0.05$.

varied from 0.41 for green-yellow vegetables to 0.84 for milk. The mean values of estimated amounts of intake of 5 food items were close and did not differ significantly, as shown in Table 6 . The ICCs varied from 0.37 for eggs to 0.78 for boiled rice between the two interviews.

\section{Discussion}

Although analytic epidemiological studies have been conducted frequently in Japan, reproducibility assessment of epidemiological information has not been widely performed on Japanese subjects. The present study was undertaken for that purpose. The age distribution of the subjects in this study is comparable to the ages of subjects who are frequently studied in relation to adult health problems. The time interval between the two interviews in this study was intended to minimize any seasonal influences, memory effect or any systematic change in personal habits over a long period of time. Since most of the 2nd interviews were conducted within 10 weeks of the 1 st interview, responses during the 2nd interview might not have been seriously biased by these factors. Reproducibility of information concerning the past history of disease, including blood transfusions, or family history of liver disease has rarely been reported. The present study showed that the reproducibility was high, but not complete.

In the present study, respondents gave relatively consistent reports for smoking habits. Similar reproducibilities, 0.820.95 in Pearson correlation coefficients, were observed by the test-retest method for 83 to 87 subjects of both sexes, aged 25-65, identified through random digit dialing in Boston. Interviews were completed twice on one of the four Health Risk Appraisal instruments at 7 to 12 week intervals (Smith et al. 1989).

The extent of the reproducibility of drinking habits observed in the present study was comparable to those for smoking habits. There is a report on the reproducibility of mean daily intake of alcohol with an ICC of 0.88 which was observed from three consecutive self-administered questionnaires performed at approximately 3 month intervals for 121 Finnish men, aged 55-69 (Pietinen et al. 1988).

Of the 12 food items, 11, all except beans, did not show statistically significant differences in the frequency distri- 
bution of intake between the two interviews. The reason for this finding with beans was not clear. Our data showed a wide range of variation for the ICCs between the two responses. Despite the effort made in the present study, the reproducibility of intake frequency for green-yellow vegetables was the lowest. The highest ICC, 0.84, was observed for milk intake. A paper from Norway on the reproducibility of the frequency of food intake observed by a self-administered questionnaire at 8 to 16 month intervals for 201 men and women aged 34-60 reported a Spearman correlation coefficient of 0.67 for intake frequency of glasses of milk per day (Jacobsen et al. 1990). Another observation with 48 subjects of both sexes aged 20-75, randomly sampled from a general population in Northern Kyushu, who were interviewed twice at $0.5-8$ month intervals showed an ICC of 0.80 on the frequency of milk intake in the year preceding the interview (Kono et al. 1988).

Studies on the reproducibility of reports on various life style measurements are still scarce in Japan and further research is needed.

Acknowledgments: The authors would like to thank the subjects in the present study for their participation and cooperation. Thanks are also due to Mrs. Hiroko Egami and Mrs. Noriko Hashimoto for their assistance.

\section{References}

Block, G. (1982). A review of validations of dietary assessment methods. Am. J. Epiedmiol. 115, 492-505.

Brinkman, G.L. and Coates, E.O. Jr. (1962). The prevalence of chronic bronchitis in an industrial population. Am. Rev. Respir. Dis. 86, 47-54.

Fukuda, K. and Shibata, A. (1991). Reliability assessment of life style measurement. Jpn. J. Cancer Clin. 37, 212-216.

Jacobsen, B. K. and BonaA, K. H. (1990). The reproducibility of dietary data from a selfadministered questionnaire. Int. J. Epidemiol. 19, 349-353.

Kono, S., Ikeda, M., Tokudome, S. and Kuratsune, M. (1988). A case-control study of gastric cancer and diet in northern Kyushu, Japan. Jpn. J. Cancer Res. 79, 1067-1074.

LeE-Han, H., McGuire, V. and Boyd, N.F. (1989). A review of the methods used by studies of dietary measurement. J. Clin.Epidemiol. 42, 269-279.

Morgan, R. W., Jain, M., Miller, A.B., Choi, N. W., Matthews, V., Munan, L., Burch, J.D., Feather, J., Howe, G.R. and Kelly, A. (1978). A comparison of dietary methods in epidemiologic studies. Am. J. Epidemiol. 107, 488-498.

Pietinen, P., Hartman, A.M., Haapa, E., Rasanen, L., Haapakoski, J., Palmgren, J., Albanes, D., Virtamo, J. and Huttunen, J. K. (1988). Reproducibility and validity of dietary assessment instruments, I A self-administered food use questionnaire with a portion size picture booklet. Am. J. Epidemiol. 128, 655-666.

Smith, K., McKinlay, S.M. and McKinlay, J.B. (1989). The reliability of health risk appraisals: A field trial of four instruments. Am. J. Public Health, 79, 1603-1607. 